\title{
Uma obra denúncia: olhares da imprensa do Rio de Janeiro sobre a Geografia da Fome
}

\author{
A work report: looks from the Brazilian press about the Geography of Hunger
}

\section{Helder Remigio de Amorim}

\author{
Doutor em História \\ Professor Assistente III da Universidade Católica de Pernambuco \\ helder.remigio@unicap.br
}

\begin{abstract}
Resumo: Este artigo problematiza a repercussão na imprensa brasileira da publicação da obra Geografia da Fome (1946) de autoria do intelectual e político Josué de Castro (1908-1973). O livro foi publicado no ambiente do Pós-guerra, momento em que as políticas públicas de combate a fome estavam na ordem do dia. Nesse sentido, o presente texto procura articular a trajetória de Josué de Castro com os debates suscitados pela publicação de Geografia da Fome no Brasil. O fim do Estado Novo e a tentativa de reconstrução da democracia representaram um momento propício para o lançamento de um livro que promoveu uma denúncia sobre a condição de desnutrição em que a maior parcela da população brasileira vivia. Desse modo, o presente texto analisa a veiculação de notícias sobre a repercussão da publicação de Geografia da Fome nos periódicos Diário de Notícias, O Jornal e Tribuna Popular, possibilitando reflexões sobre a sua dimensão humanista e de como se tornou uma referência para às políticas públicas de combate a fome.
\end{abstract}

Palavras-chave: Josué de Castro, trajetória, Geografia da Fome.

\begin{abstract}
This article discusses the repercussion in the Brazilian press of the publication of the work Geografia da Fome (1946) by the intellectual and politician Josué de Castro (1908-1973). The book was published in the post-war environment, when public policies to combat hunger were the order of the day. In this sense, this text seeks to articulate the trajectory of Josué de Castro with the debates raised by the publication of Geografia da Fome no Brasil. The end of the Estado Novo and the attempt to rebuild democracy represented a favorable moment for the launch of a book that denounced the condition of malnutrition in which most of the Brazilian population lived. Thus, this text analyzes the dissemination of news about the impact of the publication of Geografia da Fome in the newspapers Diário de Notícias, $O$ Jornal and Tribuna Popular, enabling reflections on its humanist dimension and how it became a reference for public policies of fighting hunger.
\end{abstract}

Keywords: Josué de Castro, trajectory, Geography of Hunger. 


\section{Introdução}

O presente artigo tem como intenção problematizar um momento da trajetória do intelectual e político Josué de Castro e a repercussão da publicação na imprensa do Rio de Janeiro de uma das suas obras mais conhecidas, Geografia da Fome. Esse livro publicado em 1946 pelas Edições Cruzeiro $^{1}$, teve como momento histórico o ambiente de Pós-Guerra em que a Europa tentava se reerguer e os debates em torno de políticas públicas de combate a fome estavam na ordem do dia.

Durante a Segunda Guerra Mundial houve um agravamento do problema alimentar no mundo. Uma campanha internacional que tinha como preceito buscar alternativas para eliminar o flagelo da desnutrição, teve início na Conferência Nacional de Alimentação convocada pela Liga das Nações ${ }^{2}$, em Hot Springs nos Estados Unidos, em 1943. Participaram dessa reunião aproximadamente quarenta países que se comprometeram a apagar do mapa demográfico mundial aos núcleos de populações subnutridas e famintas. A questão alimentar estava fortemente presente na agenda pública. Desse modo, no segundo pós-guerra, houve uma verdadeira "descoberta" da fome mundial, paralela ao processo de independência dos países coloniais. Esta "descoberta" levou a tentativas de conceituá-la em seus diversos níveis como fomes agudas, subalimentação crônica ou fome oculta, carências qualitativas de proteínas ou vitaminas (CARNEIRO, 2003: 24).

Nesse contexto, os estudos que tratavam da relação entre fome, pobreza e controle alimentar passaram a ter espaço, o que demonstra a circulação, apropriação e intercâmbio de ideias na obra de Josué de Castro, bem como a leitura que fazia do seu tempo. O combate à fome no Brasil foi influenciado em grande medida por experiências desenvolvidas no país entre as décadas de 1940 e 1960, por organizações, universidades, centros de pesquisa e por intelectuais que se dedicaram aos estudos de segurança alimentar, nutrição, e estratégias de combate à fome e a pobreza. A publicação de Geografia da Fome trouxe uma série de discussões em âmbito nacional

\footnotetext{
${ }^{1}$ As Edições Cruzeiro foi uma editora pertencente ao grupo do Diário Associados, fundada em 1941, era do mesmo grupo e possuía o mesmo nome de uma importante revista de variedades intitulada O Cruzeiro que circulou de 1930 até 1975. Na contracapa da primeira edição do livro Geografia da Fome encontramos a seguinte inscrição: "Este livro foi composto e impresso nas oficinas da Empresa Gráfica O CRUZEIRO S.A., Rua do Livramento, 191, Rio de Janeiro, para a sua "Seção de Livros". Superintendente - Leão Gondim de Oliveira. Diretores - Frederico G. Chateaubriand e Antonio Accioly Netto. Em dezembro de 1946" (CASTRO, 1946).

${ }^{2}$ A Liga das Nações foi uma organização internacional criada em abril de 1919, quando a Conferência de Paz de Paris adotou seu pacto fundador, posteriormente inscrito nos demais tratados de paz.
} 
sobre as condições subumanas que uma parcela significativa da população brasileira estava submetida.

Josué Apolônio de Castro nasceu em 5 de setembro de 1908 na cidade do Recife, faleceu em 1973 em Paris, durante o período em que esteve exilado após o golpe civilmilitar de 1964. A sua produção intelectual esteve aliada aos cargos públicos que ocupou como médico, professor universitário, presidente do Conselho Consultivo da $\mathrm{FAO}^{3}$, deputado federal, embaixador, e presidente do Centro Internacional de Desenvolvimento, em Paris (CID). Em relação à dimensão política e social do seu pensamento, desenvolveu ações para desnaturalizar a fome como atributo dos pobres e resultado das condições climáticas e de solo. Destacam-se, no âmbito dos debates acerca da sociedade brasileira, os estudos de Josué de Castro sobre as condições alimentares da população e as análises referentes à estrutura agrária do país.

Segundo Josué de Castro, a estrutura agrária do Brasil era arcaica e centralizadora e não permitia a diversificação de culturas. Essas ideias foram demonstradas nos seus livros mais conhecidos como Geografia da Fome (1946) e Geopolítica da Fome (1951). Mas essa preocupação esteve mais evidente no livro Sete Palmos de Terra e um Caixão (1965) no qual o autor afirma que na região Nordeste, a concentração de terras nas mãos de famílias tradicionais, seja na faixa litorânea, ou no semi-árido, bem como a efervescência dos movimentos sociais e a ineficiência das políticas públicas desenvolvidas pelo governo federal produziu tensões. No decorrer da obra apresenta soluções para enfrentar as demandas sociais da região como a transformação das estruturas econômico-sociais a partir da utilização mais racional dos recursos e a distribuição da propriedade agrícola que possibilitariam o desenvolvimento tanto da indústria quanto da agricultura.

Em 1929, Josué de Castro formou-se na Faculdade de Medicina do Rio de Janeiro. Porém foi sua atuação como professor universitário da Faculdade de Filosofia e Ciências Sociais do Recife e da Faculdade Nacional de Filosofia na capital federal que o aproximou da geografia. Ao localizar seus estudos no campo da geografia, Josué de Castro interliga, direciona e atualiza sua produção intelectual primeiramente ao nacionalismo do Estado Novo e posteriormente ao nacional-desenvolvimentismo do período democrático. É como geógrafo que obtém reconhecimento internacional, ligado

\footnotetext{
${ }^{3}$ Organização das Nações Unidas para Alimentação e Agricultura com sede em Roma-Itália.
} 
a corrente geográfica do possibilismo ${ }^{4}$ e se tornou um dos fundadores do Centro Universitário de Vincennes em 1968, na França, onde lecionou geografia até o fim da vida.

Nesse sentido, o trânsito interdisciplinar e as redes que construiu por meio dessas experiências, nos possibilitou compreender como Josué de Castro transcendeu o mundo cultural em que viveu. A partir do conceito de campo intelectual, que pode ser compreendido como uma rede de posições intelectuais variadas, que se definem pelas relações que têm entre si e pelo lugar que ocupam no campo como um todo, a autoridade ou poder simbólico dos agentes intelectuais sendo diferentes e competindo, por assim dizer, pela hegemonia (PALLARES-BURKE, 2005: 19).

A participação de Josué de Castro na proposição de políticas públicas internacionais voltadas para o combate a fome no mundo, foi paulatinamente construída a partir da circulação mundial da sua obra, que teve início em 1948 - ano da Declaração Internacional dos Direitos Humanos - quando Geografia da Fome foi publicada em língua francesa pelas Éditions Ouvrières ${ }^{5}$. Os estudos sobre essa publicação, bem como sua circulação em língua francesa, ainda é um tema carente nas produções acadêmicas que envolvem Josué de Castro, significando um campo fértil para futuras pesquisas ${ }^{6}$.

No Brasil, o fim do Estado Novo e a tentativa de reconstrução da democracia significou um momento propício para o lançamento de um livro que promoveu uma denúncia sobre a condição de desnutrição em que a maior parcela da população brasileira vivia. Assim como muitos outros intelectuais que estiveram ligados ao Estado Novo, Josué de Castro não teria muita influência no recém estabelecido Governo Dutra. O processo de construção da nação e do homem brasileiro, já não se constituía como prioridade. Seguindo uma tendência internacional do Pós-Guerra, a preocupação do Estado com os modelos de desenvolvimento passou a ser latente. Josué de Castro fará, posteriormente, a leitura dos novos movimentos e projetos políticos do Estado e

\footnotetext{
${ }^{4}$ A escola francesa de geografia, conhecida também como escola "possibilista", foi criada por Paul Vidal de la Blache e acreditava na possibilidade de haver influências recíprocas entre o homem e o meio natural. Ela traz o termo possibilismo, que foi elaborado pelo historiador Lucien Febvre para diferenciar a geografia francesa dos trabalhos influenciados pelo determinismo ambiental, da escola alemã.

5 A obra Geografie de la faim publicada pelas Éditions Ouvrières foi consultada na Biblioteca Nacional da França (BNF) durante as pesquisas do estágio doutoral realizado no Institut d'histoire du Temps Présent (IHTP).

${ }^{6}$ A maior parcela da documentação utilizada para produção deste artigo está no Acervo Pessoal de Josué de Castro (APJC) salvaguardado pela Fundação Joaquim Nabuco.
} 
adequará obras e posicionamentos a partir da noção de desenvolvimentismo dos anos 1950.

A Constituição de 1946 trazia consigo uma convergência internacional favorável à democracia representativa. A participação popular nas eleições foi fortalecida pela extensão do voto para todos os homens e mulheres maiores de 18 anos, sendo obrigatório, secreto e direto (CARVALHO, 2013: 145). A criação de novos partidos como o Partido Trabalhista Brasileiro (PTB), o Partido Social Democrático (PSD) ainda que controlados por Vargas e a cassação do registro do PCB em 1947 traduzem parcialmente o rosto daquela democracia. Os ventos democráticos estão ligados principalmente à proximidade diplomática entre Brasil e Estados Unidos, pois, de acordo com alguns autores "a diplomacia brasileira não apenas alinhava-se automaticamente com as posições americanas nas organizações internacionais, como as vezes chegava a exceder-se no apoio" (VIZENTINI, 2010: 199-200). O Brasil rompeu, em 1947, relações diplomáticas com a União Soviética e passou a compor o combate a subversão comunista, construindo uma democracia por intermédio e controle do modelo americano.

O governo Dutra promoveu uma atenção especial ao abastecimento, em detrimento das instituições que desenvolveram pesquisas no período em que Vargas esteve no poder. Apesar da mudança de direcionamento do Presidente Dutra, Josué de Castro continuou exercendo a função de autoridade no campo da alimentação no país, porém não gozava do espaço político e científico que obteve anteriormente (NASCIMENTO, 2010: 1-29). As publicações e a experiência internacional na Organização das Nações Unidas para a Educação, Ciência e Cultura (UNESCO) serão importantes para lançar suas ideias internacionalmente.

É importante ressaltar durante a década de 1930 as obras de Josué de Castro já destacavam o seu interesse por temas voltados para alimentação. Em 1932, publicou o livro O Problema Fisiológico da Alimentação no Brasil, trabalho que lhe permitiu tornar-se livre-docente pela Faculdade de Medicina do Recife. Ao longo da década de 1930, publicou estudos centrados na cidade do Recife. Por meio de uma escrita literária no conto O Ciclo do Caranguejo (1932) problematizou o cotidiano dos que fugiram da seca dos sertões e passaram a habitar os mangues. Já no estudo As Condições de Vida das Classes Operárias do Recife (1932) afirmava que os trabalhadores possuíam alimentação insuficiente e desarmoniosa nutricionalmente. Em 1937 no livro Documentário do Nordeste demonstrou consciência sobre as desigualdades sociais, 
destacando o contraste entre as antigas residências palacianas e os mocambos da capital pernambucana.

A trajetória de Josué de Castro como um intelectual que se especializou nos estudos da alimentação e da Nutrição foi paulatinamente sendo gestada, primeiramente pela participação institucional em organismos estatais como o Serviço Técnico de Alimentação Nacional e a Sociedade Brasileira de Alimentação ainda no Estado Novo. $\mathrm{O}$ acúmulo de conhecimentos em suas experiências institucionais e acadêmicas de Castro, colaboraram para a publicação de Geografia da Fome em 1946.

\section{A imprensa do Rio de Janeiro e a obra Geografia da Fome}

Geografia da Fome é considerada uma obra denúncia do flagelo da fome no Brasil. Reconhecida como um estudo cuidadoso, de escrita precisa e rigor acadêmico nas análises empreendidas, foi premiada por duas vezes. Logo após o seu lançamento pela Associação Brasileira de Escritores $^{7}$ com o Prêmio Pandiá Calógeras ${ }^{8}$ e, posteriormente, pela Academia Brasileira de Letras com o Prêmio José Veríssimo. No prêmio da Associação Brasileira de Escritores, o voto favorável do folclorista Edison Carneiro traz algumas nuances do que representou o livro Geografia da Fome:

Voto no livro de Josué de Castro, Geografia da Fome. Entre todos os livros apresentados no Prêmio Pandiá Calógeras, nenhum me parece tão nacional em caráter, nem de tema tão importante e vital, nem compreendendo tanto estudo e pesquisa, quanto este ensaio sobre o flagelo da fome. [...] O livro de Josué de Castro uma primeira e grande tentativa, na maior parte bem sucedida, de delimitar a extensão e a profundidade das carências alimentares que afligem, há mais de quatro séculos a nossa população. [...] Não creio que nenhum dos outros livros possam ter conseqüências tão tremendas quanto este sobre o pensamento social brasileiro. [...] Assim pelo que significa como

\footnotetext{
7 A Associação Brasileira de Escritores foi fundada no Rio de Janeiro em 1942 por escritores que criticavam a ausência de liberdade de expressão imposta pelo Estado Novo. Entre seus fundadores incluíam-se Otávio Tarquínio de Sousa, Sérgio Buarque de Holanda, Astrojildo Pereira, Graciliano Ramos, José Lins do Rego, Sérgio Milliet, Mário de Andrade, Oswald de Andrade e Érico Veríssimo. De acordo com a historiadora Ana Amélia Melo.

${ }^{8}$ O prêmio levou o nome de João Pandiá Calógeras que "nasceu no Rio de Janeiro, em 1870. Engenheiro, formou-se pela Escola de Minas, de Ouro Preto, em 1890. Elegeu-se deputado federal pela primeira vez em 1897, pelo Partido Republicano Mineiro (PRM). Em 1932, presidiu a Liga Eleitoral Católica (LEC) e, no ano seguinte, elegeu-se deputado federal constituinte pela legenda do Partido Progressista de Minas Gerais. Morreu em Petrópolis (RJ), em 1934”. (Dicionário Histórico Biográfico Brasileiro pós 1930, 2001).
} 
seriedade de estudo da nossa vida social, num dos aspectos mais característicos e dolorosos, e pelo significa como solução, como decisão política a tomar, este livro de Josué de Castro me parece digno do Prêmio Pandiá Calógeras, como melhor ensaio sobre assunto brasileiro de 1946 (Voto de Edison Carneiro no Prêmio Pandiá Calógeras concedido a Geografia da Fome em 1946. Acervo Pessoal Josué de Castro - FUNDAJ. Parecer sobre JC $3^{\circ}$ s. Pasta M.).

A geografia surge como elemento constituinte da divisão dos capítulos. Josué de Castro divide o Brasil em cinco regiões que se distinguem da divisão oficial de regiões do país. Nesse caso, os critérios para delimitação são as questões alimentares, as áreas de fome e de subnutrição. O livro foi dividido em cinco temas, Área Amazônica, Área do Nordeste Açucareiro, Área do Sertão do Nordeste, As Áreas de Subnutrição: Centro e Sul e por fim Estudo do Conjunto Brasileiro. O autor questiona quais são os mecanismos que levaram a sociedade, as instituições, os intelectuais a se silenciarem sobre o tema da fome: seriam esses cúmplices dos interesses políticos e econômicos? No decorrer da obra se ampara em pesquisas do campo da Nutrição que constatam que "um terço da humanidade vive em um estado permanente de fome" (CASTRO, 1946: 18).

A dimensão nacional do problema da fome no Brasil provocou impacto no recente processo de redemocratização. A opinião de Edison Carneiro, que é citado no prefácio de Geografia da Fome como um dos colaboradores, valoriza o esforço acadêmico empreendido, concedendo ao livro um estatuto inovador no âmbito do pensamento social brasileiro (BIZZO, 2009: 401-420). Essa inovação se devia principalmente pela condição de ser uma obra propositiva no âmbito das políticas públicas de combate à fome e humanista pela preocupação com a dignidade humana.

A Associação Brasileira de Escritores era formada em grande parte por intelectuais de esquerda, ligados ao $\mathrm{PCB}^{9}$. Em um momento em que a busca por novos caminhos políticos para o Brasil estava no horizonte, premiar uma obra que trazia à tona as péssimas condições sociais em que vivia o povo brasileiro, poderia apontar caminhos para combater a situação de subnutrição de uma grande parcela da população do país. As premiações colaboraram para fortalecer a circulação de Geografia da Fome. No

\footnotetext{
9 Entre os fundadores estavam também Sérgio Buarque de Holanda, Caio Prado Júnior, Astrojildo Pereira, Sérgio Milliet, Antonio Candido e diversos escritores consagrados como José Lins do Rego, Graciliano Ramos, Mario de Andrade, Raquel de Queiroz.
} 
Brasil foram nove edições, sendo a última comemorativa no centenário de Josué de Castro em 2008. A dimensão internacional do livro deve ainda ser mencionada, já que foi publicado em vinte e cinco idiomas. O prêmio da Academia Brasileira de Letras também foi registrado na revista dessa instituição.

Prêmio José Veríssimo. Parecer da Comissão. Concorreram ao prêmio Josué Veríssimo os sete volumes seguintes: 1- Geografia da Fome - Josué de Castro, 2- A margem do estilo Cruz e Souza - Antônio de Pádua, 3- Profetas de um mundo que morrre - Evaristo de Morais Filho, 4- Esboço de Filosofia - Jorge Duarte Ribeiro, 5- Comunidade ou comunismo - Manuel Joaquim Pimenta Veloso, 6- Presidencialismo - Galdino Catunda Gondim, 7- Figuras e Legendas - Sebastião Fernandes. Dêstes sete livros, pareceu-nos ser o de n.1 - Geografia da Fome, do sr. Josué de Castro - o mais importante. É um trabalho minucioso, aberto nas linhas de um panorama sociológico de larguíssimo recorte. Elaborado por um especialista em assunto da alimentação, nele as condições de vida orgânicas da população brasileira são estudadas a luz de rigorosos dados estatísticos, com o auxílio dos insubstituíveis inquéritos locais. [...] Conclusão: Propomos, pois, para o Prêmio José Veríssimo a obra A Geografia da Fome, do sr. Josué de Castro. Rio de Janeiro, 7 de maio de 1948. Múcio Leão, Relator. Manuel Bandeira, Viriato Correia (Revista da Academia Brasileira de Letras. Concursos literários de 1947. V.75, jan-jun, 1948: 277-278).

Após vencer dois prêmios e ser aceito pela comunidade acadêmica da Capital Federal, o livro Geografia da Fome, ganharia ainda muito espaço no meio intelectual e na imprensa. Naquele momento, a Academia Brasileira de Letras era uma instituição importante para conferir estatuto acadêmico e literário às obras publicadas em língua portuguesa. O parecer que reconheceu uma semelhança de Geografia da Fome com a obra de dois reconhecidos intelectuais brasileiros, Gilberto Freyre e Oliveira Viana, também colaborava para a distinção e reconhecimento do livro. Ao situar a obra no campo sociológico, o parecer também institui um lugar no campo das ciências humanas para um autor que até então era reconhecido pelas contribuições ao campo da Nutrição. Para além do mundo acadêmico, que reconheceu com os dois prêmios citados, outro meio de circulação importante para legitimar uma obra é a imprensa. 
Inúmeras matérias foram veiculadas em jornais brasileiros sobre o livro Geografia da Fome, porém na leitura da documentação notamos uma série de repetições nas análises da obra. dentre elas se destacam "Fome e Civilização" do Jornal do Brasil, Rio de Janeiro, 16 de fevereiro de 1947; "Uma Geografia da Fome" do A Tarde, Salvador, 19 de fevereiro de 1948; "Um livro que é um libelo!" de $O$ Dia, Curitiba, 18 de fevereiro de 1947; "Um cientista denuncia as áreas de fome no Brasil" de O Globo, 24 de março de 1947. Sendo assim, selecionamos aquelas que de algum modo fugiam dessa repetição e propiciaram a ampliação da discussão sobre a obra.

O Diário de Notícias ${ }^{10}$ trouxe na edição do dia 22 de dezembro de 1946 , praticamente uma resenha do livro intitulada: "Geografia da Fome. Rachel de Queiroz. Especial para o Diário de Notícias”. Nesse artigo, a escritora apresenta informações detalhadas da obra em um texto que se assemelha a uma resenha, e faz uma comparação entre a atividade do literato e a do cientista e afirma: "Diante de certos livros é que a gente vê como é fácil e sem importância o ofício de literato. Sim realmente os cientistas nos botam complexo de inferioridade" (Diário de Notícias, 22 de dezembro de 1946: 5). Promove uma reflexão sobre o fazer literário que, na opinião da autora, não busca as verdades encobertas como Josué de Castro buscou em Geografia da Fome. Quanto à escrita, afirma que "o autor segue a escola criada no Brasil pelo nosso grande Gilberto Freyre" (Diário de Notícias, 22 de dezembro de 1946: 6). As menções sucessivas que a documentação tem apresentado sobre a semelhança entre a narrativa de Freyre e Castro, não dão conta, das querelas entre esses intelectuais.

Raquel de Queiroz na última página do artigo afirma: “Aí vem esse novo "ladrão de cenas", como se diz em cinema, ou antes, ladrão de temas, roubar dos pobres romancistas o tema da fome" (Diário de Notícias, 22 de dezembro de 1946: 5). Nesse trecho a autora destaca o ineditismo do trabalho, mas também reafirma a falta de estudos específicos sobre a temática fome no Brasil. E continua: "Vejam o professor Josué de Castro, por exemplo: dedica seu livro, além de Euclides da Cunha, "a três romancistas da fome" no Brasil: Rodolfo Teófilo, José Américo de Almeida e esta sua humilde criada. E fica a gente tão radiante e honrada com a homenagem" (Diário de Notícias, 22 de dezembro de 1946: 5).

A página da dedicatória, da primeira edição de Geografia da Fome, traz as seguintes inscrições: “A Rachel de Queiroz e José Américo de Almeida autores de "O

\footnotetext{
10 Jornal carioca diário e matutino fundado em 12 de junho de 1930 por Orlando Ribeiro Dantas. Saiu de circulação em 1974.
} 
Quinze" e "A Bagaceira”, romances da Fome no Brasil” (CASTRO, 1946). Essa homenagem destaca a proximidade que Josué de Castro tinha não somente com a literatura, mas também com as ideias do que se convencionou chamar de movimento modernista, da Geração de $1930^{11}$. Os literatos que compuseram esse movimento emitiram por meio dos diversos escritos uma preocupação com as questões sociais e políticas. Por outro lado, Josué de Castro também fez a dedicatória “À memória de Euclides da Cunha e Rodolfo Teófilo, sociólogos da fome no Brasil”. Nesse último caso a homenagem a esses dois intelectuais, nomeados de sociólogos, demonstra a intenção de Josué de Castro de se aproximar conceitualmente do pensamento desses autores, o que contribuiu para circulação e aceitação da obra no meio intelectual.

Alguns meses depois o Diário de Notícias publicou outro artigo elogiando a obra, intitulado: "Fome no Brasil" de J. Fernando Carneiro. Em seu texto Carneiro afirmou: "O último livro de Josué de Castro - "A Geografia da Fome" - merece, em verdade, o interesse que vem despertando e a cópia de críticas que vem provocando" (Diário de Notícias, 02 de fevereiro de 1947: 3). Essa matéria segue o tom elogioso da publicação anterior, destacando que "o livro de Josué de Castro tem o mérito de colocar o assunto da fome na ordem do dia" (Diário de Notícias, 02 de fevereiro de 1947: 3). A fome estava paulatinamente na agenda pública brasileira, processo que foi intensificado durante a década de 1950.

O periódico O Jornal ${ }^{12}$ em 03 de janeiro de 1947, também veiculou um artigo de mesmo título "A fome no Brasil" escrito por Paul Vanorden Shaw: "poucos livros tem a arte, a ciência, ou a sorte de serem tão sugestivos e tão úteis como este, pois explica uma maneira satisfatória de toda uma série de fenômenos brasileiros" ( $O$ Jornal, 03 de janeiro de 1947: 12). O leitor pode perceber que, paulatinamente, as imagens de uma obra essencial e que torna pública a dimensão social da fome no país foi sendo construída.

\footnotetext{
11 A Geração de 1930, também conhecida como Segunda Geração Modernista, foi responsável por alçar a produção literária brasileira a novos patamares de escrita e narrativa. Faziam parte dessa geração na prosa Graciliano Ramos, José Lins do Rego, Rachel de Queiroz, Jorge Amado, Érico Veríssimo. E na poesia Carlos Drummond de Andrade, Vinicius de Moraes, Cecília Meireles, Jorge de Lima, Murilo Mendes.

${ }^{12}$ O periódico carioca $O$ Jornal assim como as Edições Cruzeiro, pertencia ao grupo Diarios Associados: foi fundado em 17 de julho de 1919 por Renato de Toledo Lopes. Cinco anos após sua fundação, foi adquirido por Francisco de Assis Chateaubriand Bandeira de Melo, tornando-se o primeiro elo e o órgão líder da cadeia dos Diários Associados. Foi extinto em abril de 1974.
} 
No entanto, em outro artigo intitulado "Ou comer é um problema econômico?", o articulista Humberto de Bastos ${ }^{13}$, também do Diário de Notícias, realiza uma série de críticas a obra, buscando o prevalecimento do econômico em detrimento do social. Para citar uma dessas afirmações: "Diz que o imperialismo econômico e o comércio internacional a serviço do mesmo, são responsáveis pela fome. Que imperialismo econômico?" (Diário de Notícias, 02 de fevereiro de 1947: 10). Para Humberto de Bastos acusar o comércio internacional como responsável pela fome, significa desconhecer que o Brasil tem um mercado consumidor pequeno em virtude do baixo padrão de vida da população daquele momento histórico.

O tom ácido daquela narrativa continuava: "As causas naturais e sociais podem influenciar outras estruturas, menos a econômica que, no nosso caso, é a determinante" (Diário de Notícias, 02 de fevereiro de 1947: 10). É possível perceber que a perspectiva analítica aborda a dimensão econômica como predominante, provavelmente, Humberto de Bastos adotava uma linha teórica marxista. Josué de Castro inicialmente não utilizou ferramentas do marxismo para analisar as causas da fome no Brasil. Mas, como já mencionamos, buscou aliar as ferramentas da geografia, da nutrição e da sociologia em um método interdisciplinar. Segundo Bizzo: "Castro situa o desajustamento econômico e social como fruto da incapacidade do Estado para servir de poder equilibrante entre interesses privados e coletivos" (BIZZO, 2012: 224).

Os embates intelectuais foram intensos no processo empreendido por Josué de Castro na tentativa de trazer novas análises para o fenômeno da fome durante toda a sua trajetória. Humberto Bastos finaliza o artigo de modo irônico: "Algumas considerações a respeito do livro do meu amigo Josué de Castro, tão bem escrito, cheio de erros seriíssimos que se avolumam e crescem quando cometidos por um homem dono de uma cátedra" (Diário de Notícias, 02 de fevereiro de 1947: 11). Os campos de disputa política e acadêmica acabam promovendo debates acirrados e que por vezes se tornam públicos, principalmente quando se trata de uma obra como Geografia da Fome, que circulou com evidência. O periódico Tribuna Popular ${ }^{14}$, ligado ao Partido Comunista Brasileiro também promoveu a crítica ao livro em questão no dia 04 de janeiro de 1947:

\footnotetext{
13 Humberto Bastos economista, jornalista e escritor. Estudioso do capitalismo brasileiro tem como principais obras são A Marcha do Capitalismo no Brasil (1944) e Produção ou Pauperismo (1946) e A Economia Brasileira e o Mundo Moderno (1948).

14 A historiadora Marieta de Moraes Ferreira nos traz informações sobre o periódico Tribuna Popular: que era um: "Jornal carioca diário, criado em 22 de maio de 1945 e fechado em dezembro de 1947, vinculado ao Partido Comunista Brasileiro (PCB). Da direção coletiva da Tribuna Popular faziam parte
} 
A Geografia da Fome do Professor Josué de Castro

Numa bela apresentação gráfica das edições Cruzeiro acaba de aparecer um livro que pelo seu conteúdo, poderá exercer um papel positivo nos debates para a solução de alguns dos problemas imediatos do povo brasileiro. Referimo-nos a Geografia da Fome. [...] Pode-se discordar de certas apreciações e conclusões do Professor Josué de Castro, mas a verdade é que entre as soluções por ele aconselhadas, para o problema, cada vez mais grave, algumas que até certo ponto coincidem com as do Partido de Prestes. [...] E sem ser marxista, seguindo como confessa os métodos da ecologia, chega porém o diretor do Instituto de Nutrição a conclusões semelhantes, em mais de um ponto fundamental, as de Prestes e seu Partido (Tribuna Popular, 04 de janeiro de 1947).

A partir do excerto acima é possível perceber como uma obra pode ser apropriada por um determinado grupo político. É fato que aquele mundo do Pós-Guerra estava dividido e o governo brasileiro, como já adiantamos, se fidelizou ao projeto estadunidense. A obra Geografia da Fome, que questionava a estrutura agrária e propunha uma melhor distribuição de renda foi, paulatinamente, sendo utilizada pelos movimentos de esquerda. Esse processo se intensificou na década seguinte, mas podemos conhecer um pouco desse começo.

$\mathrm{Na}$ análise da estrutura da página do jornal Tribuna Popular, o livro foi noticiado na sessão de política, muito próximo de outra reportagem que versava sobre "O senador do povo", Luis Carlos Prestes. A menção na matéria transcrita afirmando que Josué de Castro não era marxista, mas se aproximava dos ideários do programa do Partido Comunista, é uma questão que acompanhou toda a sua trajetória intelectual. $\mathrm{O}$ monitoramento de Josué de Castro por órgãos de vigilância política pode ser percebido nos prontuários do DOPS-RJ e DOPS-PE (Prontuário de Josué Apolônio de Castro. N ${ }^{\circ}$ 600. DOPS-RJ. Acervo do APERJ e Prontuário de Josué Apolônio de Castro. $\mathrm{N}^{\circ}$ 10.691. DOPS-PE), que apontam a participação de Josué de Castro em eventos, reuniões e destacam a aproximação com os setores da esquerda brasileira, a partir de

Pedro Mota Lima, Álvaro Moreira, Aidano do Couto Ferraz, Dalcídio Jurandir e Carlos Drummond de Andrade. A equipe do jornal era integrada tanto por comunistas como por não-comunistas. Além de participar de campanhas em que se envolveu toda a imprensa do país, a Tribuna Popular caracterizou-se pela defesa constante do trabalhador em sua luta contra os empregadores, posição essa que lhe valeu grande popularidade. Logo nos primeiros meses de vida, o jornal manteve uma periodicidade diária, chegando a atingir, uma tiragem de 123 mil exemplares". Disponível em www.cpdoc.fgv.br/ verbetes, acessado em 26 de junho de 2015. 
meados da década de 1940. Essa proximidade com o campo da esquerda e a mudança de perspectiva de análise da obra de Josué de Castro, quando passou a criticar os rumos da política e da economia no Brasil, contribuiu para que fosse posteriormente, na década de 1960, nomeado de comunista pelos órgãos de vigilância.

Em uma reportagem de capa de outra edição, o jornal Tribuna Popular, trouxe a seguinte manchete: "O aniversário de Prestes comemorado em todo Brasil. Escritores e artistas falam sobre o aniversário de Prestes" (Tribuna Popular, 03 de janeiro de 1947). Entre os escritores estavam Graciliano Ramos, Barão de Itararé e Josué de Castro, que teceu comentários elogiosos: "Luís Carlos Prestes terá um grande papel a representar na luta tenaz que as forças democráticas terão que desenvolver no mundo inteiro para sufocar as últimas e renitentes forças fascistas”. Nessa declaração, Josué de Castro reconhece a importância política de Prestes e se coloca também no campo de combate contra o fascismo no mundo. Naquele momento, o PCB vivenciava dias difíceis, pois foi extinto em 1947 e, no ano seguinte, teve todos os mandatos de políticos que pertenciam ao partido cassados ${ }^{15}$.

A imprensa brasileira continuou veiculando matérias e textos sobre o livro Geografia da Fome. No periódico O Jornal, havia uma coluna dedicada a livros da área de Ciências Humanas, intitulada História, assinada pelo historiador e então diretor da Biblioteca Nacional, José Honório Rodrigues. O livro de Josué de Castro foi lembrado no artigo "Alguns novos livros de História":

[...] Não queremos, ainda, deixar de mencionar a Geografia da Fome. A fome no Brasil do Sr. Josué de Castro, que não sendo também um livro de história, é registrado porque deve merecer a atenção dos estudiosos dos problemas brasileiros. $\mathrm{O}$ autor resolver encarar o problema da fome no Brasil, não do ponto de vista puramente fisiológico, mas num plano de conjunto, onde se destacam as ligações, influências e conexões de múltiplos fatores que interferem na manifestação do fenômeno. Seu método foi geográfico, sem que, por disso se tenha tornado o seu estudo uma monografia geográfica da fome. Viu também aspectos médicos, biológicos e higiênicos, não descurando da perspectiva histórica. Examinou a parte que a

\footnotetext{
15 No que concerne a cassação dos mandatos de políticos do PCB: "A 10 de janeiro de 1948, foram cassados os mandatos de todos os comunistas eleitos ao longo da legalidade do partido. Os efeitos da cassação foram dramáticos para a organização e a linha política do PCB. Os caminhos institucionais de acesso ao movimento sindical estavam cortados, bem como os canais parlamentares" (SILVA, 2007: 115).
} 
fome representou na evolução de nossa vida, apontou fatos novos, explicou vários problemas específicos, do trabalhador brasileiro, negro ou branco, sertanejo ou citadino. Ao terminar o trabalho, que se mostrou rico na consulta e utilização de dados históricos, o autor chegou, entre outras conclusões, a de que a fome no Brasil, é antes de tudo, do seu passado histórico (O Jornal, 22 de janeiro de 1947: 6).

A dimensão histórica da obra de Josué de Castro é pouco ou quase não lembrada nos diversos trabalhos acadêmicos sobre o autor. A escrita de Castro, especialmente em Geografia da Fome, questiona a estrutura agrária do Brasil que até hoje é essencialmente amparada no latifúndio. Josué de Castro constata, na década de 1940, que o passado da colonização portuguesa contribuiu para que o Brasil tivesse uma concentração fundiária perversa, que contribuía substancialmente para cerceamento do direito à alimentação de uma parcela significativa da população. Nesse sentido, compreender que a fome é um fenômeno social, não seria possível sem estudar o tema localizado no tempo e nas relações entre os homens. A história enquanto disciplina, apesar de não ser uma ferramenta explicita na estrutura da obra, foi utilizada pelo autor como um mecanismo para a leitura do presente:

[...] ao final da década de 1940, a produção de Josué de Castro aponta, como ideia básica, a compreensão da fome como um processo intimamente relacionado a um certo perfil histórico de consolidação das estruturas econômicas, políticas e sociais do país. É com esse ponto de vista que o autor constrói sua argumentação, contrapondo uma organização da sociedade geradora de fome, e em outro extremo, um conjunto de transformações da realidade, capaz de emancipar a população da grave situação alimentar em que vive (MAGALHÃES, 1997: 55).

Por meio desse debate, ao defender uma mudança da estrutura fundiária do Brasil, Josué de Castro se coloca em um campo de contestação das estruturas sociais vigentes $^{16}$, aliando-se às lutas populares no momento histórico que antecede o golpe civil-militar no Brasil. Principalmente a partir de 1945, setores ligados ao PTB (Partido

\footnotetext{
16 Ainda em relação a sua obra é importante mencionar que as edições dos livros Geografia da Fome e Geopolítica Fome, que circularam durante a década de 1950 e início dos anos 1960, foram sendo levemente reformuladas de acordo com as demandas sociais e novas redes onde passou a circular, numa tentativa de atualizá-las e colocá-las no centro dos debates do Estado.
} 
Trabalhista Brasileiro) passaram a defender a ideia de que por meio de reformas das estruturas socioeconômicas do Brasil seria possível chegar ao desenvolvimento e ao bem estar da sociedade.

A circulação de Geografia da Fome e a atuação de Josué de Castro como um intelectual que apontava caminhos para o combate a fome, colaboraram para que conquistasse espaço, não apenas no meio intelectual brasileiro, mas também em âmbito internacional. As nações se reuniam para criar organizações que dessem conta dos problemas que ainda persistiam no Pós-guerra. Nesse sentido, "a criação de instituições interestatais, de normas de direito internacional e de armas de combate ao flagelo da fome" (ZIEGLER, 2013: 109) contribuíram para a criação de projetos, debates e políticas públicas que visavam superar o problema.

\section{O discurso de Josué de Castro se lança para o mundo}

Em meio aos conflitos da Segunda Guerra Mundial passou-se a discutir em âmbito internacional, a criação de uma entidade que auxiliasse as nações nos conflitos diplomáticos e que estivesse próxima das causas humanitárias. O sistema organizacional da Organização das Nações Unidas (ONU), concebido entre 1942 e 1945, pelos países vencedores da guerra, tinha a intenção de manter a paz conquistada que significava a manutenção da ordem, que tinham estabelecido com a sua vitória (BERTRAND, 1995: 10).

Com o estabelecimento da ONU, o campo da alimentação passou a fazer parte das prioridades institucionais de diversos países. Em 1946, na cidade de Quebec, no Canadá, houve uma reunião com Estados membros das Nações Unidas que realizou a primeira conferência da Organização para Alimentação e Agricultura (FAO) ${ }^{17}$. A finalidade dessa nova instituição era promover a igualdade de distribuição dos alimentos entre a humanidade, de combater e erradicar a fome (ZIEGLER, 2013: 110).

Nesse momento de criação de instituições que permitam acompanhar as tensões mundiais, também houve a elaboração de leis e decretos voltados para os direitos do homem. A Declaração Universal dos Direitos Humanos (1948) traz em seu artigo $25^{\circ}$, o direito à alimentação. O livro Geografia da Fome obteve reconhecimento nos meios intelectuais e teve sua circulação favorecida pelas condições e discursos daquele

\footnotetext{
${ }^{17}$ Trataremos especificamente da FAO e da contribuição de Josué de Castro para essa instituição no quarto capítulo desta tese.
} 
momento histórico. Josué de Castro passou a ser convidado para participar de conferências e palestras promovidas pela ONU. O periódico Diário de Notícias noticiou em 20 de outubro de 1948 o decreto que autorizava Josué de Castro a representar o Brasil como um dos delegados na Conferência Geral de Organização das Nações Unidas para Alimentação e Agricultura, na capital dos Estados Unidos. Nessa mesma conferência, Josué de Castro foi eleito "Vice-Presidente da Comissão de Atividades Técnicas".

Representarão o Brasil na Conferência da ONU para Alimentação e Agricultura. O Presidente da República assinou um decreto autorizando Newton de Castro Neleza, Josué de Castro, Antônio da Cunha Bairra, e Armando Peregrino e o Cônsul Geral Valder Lima Sarmanho, este como delegado-chefe e aqueles como delegados do Brasil à Conferência Geral de Organização das Nações Unidas para Alimentação e Agricultura a realizamse em Washington em novembro próximo (Diário de Notícias, 20 de outubro de 1948: 2).

Josué de Castro começa a se mover em organismos internacionais, representando o Brasil, adequando o discurso de combate a fome ao que estava sendo discutido internacionalmente. No regresso da conferência afirmou: "a fome é a maior sabotadora da paz no mundo" (A Noite, 24 de novembro de 1948: 5). Em uma reportagem veiculada pelo Diario Popular de São Paulo, relatou algumas impressões sobre a conferência:

Regressou dos estados Unidos o Prof. Josué de Castro, que representou o Brasil na Conferência da Organização de Alimentação e Cultura. O Prof. Josué de Castro assinalou que foi debatido naquele certame o grave problema da malária, chegando-se a conclusão que a principal causa é a subnutrição. Depois de outras considerações, afirmou: "A luta mundial contra a fome" foi o tema central da minha conferência em que tomei parte. Interrogado sobre as conclusões alcançadas nesse terreno, disse-nos: Concordaram os delegados dos 56 países membros da Organização que a fome, o maior sabotador da paz no mundo, além de ser um fenômeno universal, é uma praga feita pelo homem. Dois terços da humanidade em todos os continentes, sofrem de fome, endêmica ou epidemicamente. Sobre as causas dessa situação, disse o prof. Josué de Castro: - Existe no mundo grande desequilíbrio entre as necessidades de consumo e a produção de 
alimentos. A deficiência de produção, entretanto, não pode ser atribuída a condições naturais, mas a incapacidade do homem de aproveitar essas condições. No Brasil a área aproveitada para a produção de alimentos é de menos de $1 \%$ do território nacional (Diario Popular, 28 de dezembro de 1948: 6).

As construções discursivas atendem a determinadas interdições, a historicidade e ao ato impositivo de verdade. No caso específico da reportagem, Josué de Castro apresenta a necessidade de atrelar as ideias defendidas em Geografia da Fome ao discurso institucional da FAO. A ideia de denunciar a fome não estava mais na agenda pública, o que vigorava era a necessidade de reunir condições para combater o problema. Nessa reportagem, podemos identificar o início de uma luta que tomou dimensões internacionais, passando por diversas instituições, Josué de Castro procurou criar mecanismos que atacassem diretamente a fome (REZENDE, 2012: 511).

A circulação dos livros, palestras, conferências e articulações tecidas por Josué de Castro, tanto no âmbito universitário, quanto no campo da política, propiciaram a sua participação em organismos internacionais como a FAO, primeiramente como membro e posteriormente como presidente, entre os anos de 1952 e 1954. Apesar de sua obra e da atuação político-intelectual terem contribuído para colocar na agenda pública brasileira e na ONU questões que norteiam o problema alimentar, suas idéias, em alguns momentos, enfrentaram resistências das potências mundiais.

A Organização de Educação, Ciência e Cultura das Nações Unidas desejou apurar a questão da alimentação pública na América do Sul e incumbiu de um estudo especial o professor brasileiro Josué de Castro, conhecedor da matéria, autor de estudos vários e diretor do Instituto de Alimentação da Universidade do Brasil. O trabalho do professor Josué de Castro vem compor uma separata do volume de trabalhos e pesquisas. O resultado do estudo, em linhas gerais, foi a verificação de que na América do Sul, ao contrário de ser um El Dorado em que foi tida por largo tempo contém uma população subalimentada. [...] A conclusão do estudo do professor Josué de Castro, declarando que o regime agrícola sul-americano de tipo semicolonial á base de uma exploração semi-feudal do solo, utilizando processos agrícolas arcaicos e de manifesta tendência a monocultura latifundiária, apresenta um coeficiente de produção alimentar muito abaixo das 
necessidades biológicas da população (Diario Popular, 28 de dezembro de 1948: 6).

Nesse sentido, a atividade institucional não esteve dissociada da produção intelectual. Em 1949, a aproximação com a UNESCO possibilitou a publicação do estudo: Os problemas da alimentação na América do Sul. Escrever um trabalho para a UNESCO significava garantir a circulação internacional nos países membros da organização, bem como facilitar o intercâmbio de ideias e acesso a outros modos de pensar. O periódico O Jornal em 09 de junho de 1949 veiculou uma nota sobre o estudo na seção Publicações:

Os problemas da alimentação na América do Sul é o título de uma separata da revista "Trabalhos e Pesquisas" mandada editar pelo Instituto de Nutrição da Universidade do Brasil. Trata-se de um trabalho de cerca de 30 páginas, especialmente elaborado a pedido da UNESCO pelo professor Josué de Castro para ser divulgado em vários idiomas destinado a servir de roteiro para os debates que, a respeito, serão levados a efeito este ano nos países aderidos a esse organismo internacional. (O Jornal, 09 de junho de 1949).

Analisando a situação fundiária da América do Sul, assim como fez em termos de Brasil em Geografia da Fome, o tema fundiário, aliado à reforma agrária, estará presente na atuação de Josué de Castro, nos anos 1950 e início dos anos 1960, como um instrumento necessário para o combate a fome. Le problème de l'álimentation en Amérique du Sud circulou por todos os continentes, distribuído pela UNESCO, foi publicado em língua inglesa, francesa e espanhola. Ao lançar uma problemática voltada para a alimentação na América do Sul, Josué de Castro antecipava algumas das suas preocupações do livro Geopolítica da Fome, publicado em $1951^{18}$.

A partir das discussões apresentadas ao longo do texto esperamos ter construído possibilidades de interpretação sobre a circulação e a crítica de alguns periódicos do Rio de Janeiro sobre o livro Geografia da Fome. Revisitar o pensamento de Josué de Castro em um momento histórico no qual a insegurança alimentar volta a atingir o Brasil se constitui como um importante compromisso do historiador de construir diálogos com as demandas sociais do presente.

\footnotetext{
18 Informações obtidas em consulta realizada na Biblioteca e no Arquivo da UNESCO em Paris
} (UNESCO Archives. COM.COL.HN/01) 


\section{Fontes}

Acervo Pessoal Josué de Castro - Fundação Joaquim Nabuco (FUNDAJ)

Voto de Edison Carneiro no Prêmio Pandiá Calógeras concedido a Geografia da Fome em 1946. Parecer sobre JC $3^{\circ} \mathrm{s}$. Pasta M.

Diário de Notícias, Rio de Janeiro, 22 de dezembro de 1946, p. 3-6. Pasta 16.

O Jornal, Rio de Janeiro, 03 de janeiro de 1947, p. 12. Pasta 16.

O Jornal, Rio de Janeiro, 22 de janeiro de 1947, p. 6. Pasta 16.

O Jornal, Rio de Janeiro, 09 de junho de 1949. Pasta 15.

Diário de Notícias, Rio de Janeiro, 02 de fevereiro de 1947, p. 3. Pasta 16.

Diário de Notícias, Rio de Janeiro, 02 de fevereiro de 1947, p. 10-11. Pasta 16.

Diário de Notícias, Rio de Janeiro, 20 de outubro de 1948, p. 2. Pasta 15.

Tribuna Popular, Rio de Janeiro, 03 de janeiro de 1947, p. 3. Pasta 16.

Tribuna Popular, Rio de Janeiro, 04 de janeiro de 1947, p. 12. Pasta 16.

Diario Popular, São Paulo, 28 de dezembro de 1948, p.6. Pasta 15.

Acervo da Academia Brasileira de Letras - Rio de Janeiro

Revista da Academia Brasileira de Letras. Concursos literários de 1947. V.75, jan-jun, 1948, p. 277-278. Biblioteca Acadêmica Lúcio de Mendonça.

DOPS-PE - Acervo do Arquivo Público Estadual João Emerenciano (APEJE)

Prontuário de Josué Apolônio de Castro. Nº 600. DOPS-RJ

DOPS-RJ - Acervo do Arquivo Público do Estado do Rio de Janeiro (APERJ)

Prontuário de Josué Apolônio de Castro. No 10.691. DOPS-PE.

Arquivo da UNESCO - Paris

CASTRO, Josué. Le problème de l'álimentation en Amérique du Sud. Paris: UNESCO/ DUNOD, 1950. Archives. COM.COL.HN/01

\section{Referências bibliográficas}

BIZZO, Maria Letícia Galluzzi (2009). Ação política e pensamento social em Josué de Castro. Bol. Mus. Para. Emílio Goeldi. Ciências. Humanas, Belém, v. 4, n. 3, pp. 401-420, set.- dez.

CARVALHO, José Murilo de (2013). Cidadania no Brasil: o longo caminho. Rio de Janeiro: Civilização Brasileira.

CARNEIRO, Henrique (2003). Comida e Sociedade. Uma história da alimentação. Rio de Janeiro: Elsevier.

CASTRO, Josué de (1946). Geografia da Fome. A Fome no Brasil. Rio de Janeiro: Edições Cruzeiro.

CASTRO, Josué de (1959). Geopolítica da Fome. São Paulo: Editora Brasiliense.

CASTRO, Josué (1950). Le problème de l'álimentation en Amérique du Sud. Paris: UNESCO/ DUNOD.

CASTRO, Josué (1965). Sete Palmos de Terra e um Caixão. Ensaio sobre o Nordeste uma Área Explosiva. São Paulo: Editora Brasiliense. 
DELGADO, Lucília Neves (2001). Trabalhismo, desenvolvimentismo: um projeto para o Brasil. In: FERREIRA, Jorge (Org.). O populismo e a sua história: debate e crítica. Rio de Janeiro: Civilização Brasileira.

Dicionário Histórico Biográfico Brasileiro pós 1930 (2001). 2 ed. Rio de Janeiro: Ed. FGV.

DOSSE, François (2009). O Desafio Biográfico. Escrever uma vida. São Paulo: Editora da Universidade de São Paulo.

FERREIRA, Marieta de Moraes (2006). Getúlio Vargas: uma memória em disputa. Rio de Janeiro: CPDOC.

GUERELLUS, Natália de Santanna (2015). Como um castelo de cartas: culturas políticas e a trajetória de Rachel de Queiroz (1910-1964). Tese (Doutorado) Universidade Federal Fluminense, Departamento de História.

JUDT, Tony (2011). Pós-Guerra: uma história da Europa desde 1945. Rio de Janeiro: Objetiva.

(2010). Reflexões sobre um século esquecido, 1901-2000. Rio de Janeiro: Objetiva.

MAGAlHÃES, Rosana (1997). Fome: uma (re) leitura de Josué de Castro. Rio de Janeiro: FIOCRUZ.

NASCIMENTO, Renato Carvalheira do (2010). Três Combates da Fome no Brasil: Josué de Castro, Betinho e Dom Hélder Câmara. VIII Congresso Latino Americano de Sociologia Rural, Porto de Galinhas - PE, novembro, pp. 1-29.

PALLARES-BURKE, Maria Lúcia Garcia (2005). Gilberto Freyre: um vitoriano nos trópicos. São Paulo: Editora da UNESP.

Revista da Academia Brasileira de Letras (1948). Concursos literários de 1947. V.75, jan-jun, pp. 277-278.

REZENDE, Maria José de (2012). Geopolítica da Fome: uma obra esclarecedora das nuanças básicas de um debate político sobre as populações pobres no mundo. In: SILVA, Tânia Elias Magno (Org.). Josué de Castro. Rio de Janeiro: Fundação Miguel de Cervantes.

SILVA, Fernando Teixeira da (2007). O equilibrista e a política: o "Partido da Classe Operária" (PCB) na democratização (1945-1964). In: FERREIRA, Jorge. REIS, Daniel Aarão. Nacionalismo e Reformismo Radical (1945-1964). As esquerdas no Brasil; v.2. Rio de Janeiro: Civilização Brasileira.

VIZENTINI, Paulo G. Fagundes (2010). Do Nacional-desenvolvimentismo à Política Externa Independente (1945-1964). In: DELGADO, Lucília de Almeida Neves. FERREIRA, Jorge (Orgs.). O Brasil Republicano. O tempo da experiência democrática: da democratização de 1945 ao golpe civil-militar de 1964; v.3. Rio de Janeiro: Civilização Brasileira.

Recebido em: 15 de agosto de 2021.

Aprovado em: 07 de dezembro de 2021.

DOI: $10.12957 /$ intellectus.2021.61696 